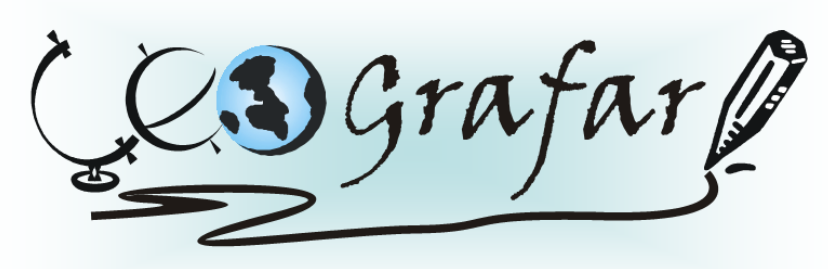

Revista Eletrônica do Programa de Pós-Graduação em Geografia - UFPR

\title{
AS AÇÕES ANTRÓPICAS E AS FORMAÇÕES TECNOGÊNICAS: O CASO DO JARDIM HUMBERTO SALVADOR EM PRESIDENTE PRUDENTE-SP
}

\author{
LEDA CORREIA PEDRO ${ }^{1}$ \\ JOÃO OSVALDO RODRIGUES NUNES ${ }^{2}$
}

\begin{abstract}
Resumo: As formações tecnogênicas são decorrentes das ações antrópicas, compreendidas no contexto das relações entre sociedade e natureza. Segundo Peloggia (1998), toda intervenção social na natureza causam conseqüências que podem se materializar em três formas: primeiro seriam as resultantes da modificação do relevo (forma), em segundo lugar as alterações na dinâmica geomorfológica (processos geomorfológicos) e por último a criação de depósitos correlativos. Com a intenção de identificar estas dinâmicas e as formações tecnogênicas resultantes das ações antrópicas, adotou-se como área de estudo o Jardim Humberto Salvador, loteamento localizado na zona norte da cidade de Presidente Prudente/SP, considerado como área de exclusão social. Neste loteamento identificaram-se vários níveis de formações tecnogênicas resultantes das dinâmicas existentes no local.
\end{abstract}

Palavras-chave: Formações Tecnogênicas; Geomorfologia Urbana; Ação Antrópica.

\section{THE ANTHROPIC ACTIONS AND TECHNOGENICS FORMATIONS: THE CASE OF JARDIM HUMBERTO SALVADOR IN PRESIDENTE PRUDENTE-SP}

\begin{abstract}
The technogenic formations are the results of the anthropic actions in the context of the relationship between society and nature. According to Pellogia (1998), all social intervention in nature causes consequences that can be materialize in three ways: first it would be the result of the modification of relief (form) secondly, it would be the changes in the geomorphological dynamics (geomorphological processes) and finally, it would be the creation of correlatives deposits. To identify these dynamics and technogenic formations which are resulting of the anthropic actions we adopted as the study area the Jardim Humberto Salvador, located in the north of the city of Presidente Prudente, São Paulo State, considered as an area of social exclusion. In this residential area we identified various levels of technogenic formations resulting from the dynamics of the local.
\end{abstract}

Keywords: Technogenic Formations; Urban Geomorphology; Anthropic Action.

Resumen: Las formaciones de los depósitos tecnogénicos son los resultados de la acción antropica, comprendidas en el contexto de las relaciones entre sociedad y naturaleza. Segundo Pellogia (1998), todas las intervenciones sociales en la naturaleza causan consecuencias que se pueden materializar en tres formas: primero, serían los resultados de la modificación de lo relieve (forma), en según lugar serían las alteraciones en la dinámica geomorfológica (procesos geomorfológicos) y finalmente serían de la creación de los depósitos correlativos. Con la intención de identificar estas dinámicas y las formaciones tecnogénicas resultantes de las acciones antropicas, adoptamos el Jardim Humberto Salvador como área del estudio, que es un área residencial situada en el norte de la ciudad de

\footnotetext{
${ }^{1}$ Professora celetista do ensino médio e fundamental do Estado de São Paulo e Mestre em Geografia pelo curso de Pós-Graduação em Geografia da FCT/UNESP/Presidente Prudente. Correio eletrônico: ledacpgeo@yahoo.com.br

${ }_{2}^{2}$ Professor dos Cursos de Graduação e de Pós-Graduação em Geografia da FCT/UNESP/Presidente Prudente. Correio eletrônico: joaosvaldo@fct.unesp.br
} 
Presidente Prudente/SP y es considerada como área de exclusión social. En esta área urbana identificamos varios niveles de formaciones tecnogénicos resultantes de las dinámicas existentes en aquel local.

Palabras-clave: Formaciones Tecnogénicas; Geomorfología Urbana; Acción Antropica.

\section{INTRODUÇÃO}

A apropriação e ocupação dos compartimentos geomorfológicos em áreas urbanas e os impactos decorrentes desta dinâmica é o enfoque primordial da investigação geográfica que apresentaremos a seguir.

O estudo é realizado a partir da análise da dinâmica de apropriação e ocupação do relevo no bairro ${ }^{3}$ Jardim Humberto Salvador, localizado na zona norte da cidade de Presidente Prudente - SP.

Esta investigação buscou compreender, em primeiro lugar, como a ação antrópica esculturou este relevo para, em seguida, entender como a dinâmica de apropriação e ocupação criaram novas formas de relevo de origem tecnogênica neste ambiente urbano.

Para a realização desta análise, utilizamos como recorte temporal o período técnico-científico-informacional. Neste período "os objetos técnicos tendem a ser ao mesmo tempo técnicos e informacionais, já que, graças à extrema intencionalidade de sua produção, e de sua localização, eles já surgem como informação" (SANTOS, 2006, p.238). A ciência, a técnica e a informação formam a tríade da produção do mundo atual. É neste período que o homem, ou melhor, a sociedade, passa a ser um agente esculturador do relevo, pois suas intervenções no ambiente tornaram-se mais intensas e aceleradas neste recorte histórico-temporal.

No período supracitado, os impactos nos ambientes naturais e urbanos são um dos temas centrais das discussões mundiais. Estes impactos são provocados principalmente pelas necessidades de manter um padrão de consumo da dita "sociedade consumista" que, por sua vez, é instigada principalmente pela mídia para consumir cada vez mais produtos. Assim, temos a aceleração do processo produtivo que, para manter este padrão de produção, explora-se cada vez mais os recursos

\footnotetext{
${ }^{3} \mathrm{O}$ bairro pode ser entendido como uma mediação entre o espaço privado (da casa, da família) e o público, entre a vida familiar e as relações societárias mais amplas. De tal forma que ele é o lócus de uma sociabilidade intermediária, baseada em larga medida no compartilhamento de referenciais espaciais comuns, como o espaço do encontro, construído no nível da vida cotidiana.
} 
naturais, degradando e esculturando as formas superficiais do ambiente em que vivemos.

O mundo vive um período no qual os fenômenos ocorrem em escala global, mas atrelado a escala local. Somente a título de exemplo, podemos citar o caso do buraco da camada de ozônio localizado na Antártica que, num primeiro momento, pode parecer um problema ambiental local. No entanto, os impactos daquele local, como o derretimento das calotas polares, leva ao aumento no nível do mar e a geração de problemas socioambientais a nível global, como as inundações das áreas litorâneas.

Ainda no que se refere ao período em que vivemos, Santos (2006, p.238) nos diz que, "a ciência e a tecnologia, junto com a informação, estão na própria base da produção, da utilização e do funcionamento do espaço e tendem a construir um substrato". Antes apenas os grandes centros urbanos apresentavam estas técnicas ligadas às pesquisas científicas, mas atualmente por meio dos objetos informacionais, isso se expandiu por todo o mundo, englobando também as cidades de menor porte.

Mudou-se o modo de vida, no qual se compram mais e se descartam mais. A facilidade de comunicação e divulgação de informações ocorre de forma cada vez mais intensa. Este tempo histórico que envolve o período técnico-científicoinformacional permite uma transformação muito mais acelerada da paisagem, no qual se predominam os objetos artificiais.

Com a aceleração do processo produtivo, a sociedade capitalista consome mais produtos de pouca durabilidade. Assim, temos um aumento dos materiais descartáveis e, conseqüentemente, os resíduos sólidos tornam-se mais presentes no que se refere à quantidade de lixo produzido.

Segundo Suertegaray (2002, p. 48), é neste contexto que a Geomorfologia, passa a considerar em seus estudos o homem como um agente geomorfológico, pois sua força de atuação é visualmente percebida por todo planeta. Assim, este olhar nos leva a pensar o tempo geomorfológico em uma perspectiva no qual o homem é considerado um agente modelador do relevo. 
Neste contexto em que se insere o ponto de vista do tempo que faz (SUERTEGARAY e NUNES, 2001), no qual o momento histórico vivido é regido pelo desenvolvimento da técnica, da ciência e da informação, alguns pesquisadores como os geógrafos passam a dar mais importância aos estudos e análises dos processos morfodinâmicos (tempo curto) do que dos processos morfogenéticos.

A partir deste ponto de vista, a ação do homem torna-se mais evidente no que tange a esculturação dos compartimentos geomorfológicos. Esta esculturação pode se manifestar de diversas maneiras, seja por meio da instalação de um loteamento, com a utilização de obras de terraplenagem, ou pela construção de um aterro sanitário, dando origem a verdadeiras colinas constituídas por resíduos sólidos.

Entre os resíduos sólidos, existem alguns materiais que são identificados como úrbicos (PELOGGIA, 1998), tais como detritos urbanos e materiais terrosos, que contêm artefatos manufaturados pelo homem moderno como tijolos, vidros, concreto, asfalto, prego, plástico, metais variados etc.

Os materiais úrbicos são decorrentes do período técnico-científico e ganharam muito mais destaque no período técnico-científico-informacional. Isto se justifica pela intensa extração de matérias-primas do ambiente natural, que muitas vezes são realizadas sem um manejo adequado e sustentável com objetivo de aumentar a produtividade. Dessa forma, os impactos socioambientais tornam-se ainda mais amplos (no sentido de manifestação no espaço) e complexos (modifica a dinâmica dos processos naturais).

Este período demonstra como as relações da sociedade (homem-homem) interferem na dinâmica da natureza (ambiente natural). É neste ponto que a sociedade torna-se o agente esculturador dos compartimentos geomorfológicos (topos, vertentes e fundos de vales) mais significativos, principalmente na escala local, na perspectiva do tempo que faz.

A dinâmica da sociedade, no contexto da produção de um loteamento, envolve diferentes agentes de produção do espaço urbano, tanto públicos quanto privados. Cada um possui um papel muito importante, tanto no que se refere à implantação do loteamento como na qualidade de vida dos moradores. 
Esses agentes são, na maioria das vezes, responsáveis pelas leis de implantação do loteamento e pelo conjunto das instalações necessárias às atividades humanas, como rede de esgotos e de abastecimento de água, energia elétrica, coleta de águas pluviais, rede telefônica e gás canalizado etc.

A dinâmica da natureza ${ }^{4}$, diante da implantação de um loteamento, é totalmente alterada, os ciclos naturais são redirecionados e passam a desenvolver novas dinâmicas, que resultam em diversos impactos no ambiente.

Perante este fato, podemos destacar os impactos que afetam a dinâmica hídrica e o processo geomorfológico.

Os fluxos pluviais são redirecionados tanto pelas ruas, quanto pelas redes de captação de águas da chuva. Estes redirecionamentos provocam concentração destes fluxos hídricos e tem como conseqüência o aumento do volume das águas superficiais em forma de enxurradas, que arrastam restos de materiais tecnogênicos (lixo, entulho, plástico etc.). Outra alteração provocada pela ação humana seria no processo geomorfológico, neste caso, as vertentes passam a ser esculturadas de forma acelerada, assim os sedimentos são deslocados para áreas mais a jusante do relevo e provocam o assoreamento dos cursos d'águas e o aparecimento de processos erosivos.

A inter-relação da dinâmica da sociedade e da natureza, neste contexto, está contribuindo para a formação de novas configurações superficiais, denominados relevos tecnogênicos. Para Peloggia et.al. (2005), o conjunto destas formações são os ambientes tecnogênicos, que se caracterizam por serem transformados principalmente pelas práticas agrícolas, pelo processo de urbanização, mineração, entre outras.

A transformação no ambiente causada pela sociedade, por meio da técnica atrelada à informação, alterou diretamente e/ou indiretamente os processos geológicos, geomorfológicos etc. Esta transformação surge na Terra com o homem e, a cada período histórico, a ação antrópica torna-se mais expressiva neste processo. Temos a criação e a inserção de novas substâncias presentes em produtos utilizados no dia-a-dia, e quando descartados erroneamente, estes

\footnotetext{
${ }^{4}$ Essa dinâmica já não é integralmente natural, pois já sofreu alterações no processo de ocupação das paisagens, no caso da região de Presidente Prudente/SP.
} 
materiais (resíduos) acabam fazendo parte dos aterros, sejam eles sanitários ou não. Os aterros também constituem as morfologias tecnogênicas.

Diante deste quadro, enfatiza-se a importância de se debater a dinâmica de apropriação e ocupação do relevo em áreas urbanas e a constituição de morfologias tecnogênicas. Assim, esta pesquisa busca contribuir para o debate acerca da relação da sociedade e da natureza perante da produção do espaço urbano, enfocando o caso dos depósitos tecnogênicos no Jardim Humberto Salvador.

Esta análise é válida perante aos problemas socioambientais decorrentes da produção do espaço urbano, quando nos referimos à implantação de loteamentos. Muitas vezes, quando o loteamento é implantado, os agentes produtores deixam de fazer análises integradas das condições ambientais e sociais da área. Neste caso, quando a dinâmica da natureza (processos geomorfológicos, pedológicos, atmosféricos etc.) não é considerada e articulada com a interferência social, podemos ter nestes ambientes graves conseqüências no que se refere aos impactos.

O objetivo que norteia esta investigação é compreender a dinâmica da sociedade e da natureza diante da ação antrópica na constituição de um loteamento. Perante esta dinâmica, procuramos identificar e entender como são gerados os relevos tecnogênicos.

\section{MATERIAIS E MÉTODOS}

\section{Materiais}

Para a concretização da pesquisa, foram adotados os materiais e procedimentos a seguir:

- Carta planialtimétrica de Presidente Prudente, na escala de 1:10.000 de 1996, para realizar as correções ortogonais dos contornos das feições geomorfológicas, construída a partir das fotografias aéreas;

- Fotografias aéreas em preto e branco, na escala de 1:25.000 de 1995, no qual foram identificados os três compartimentos mais simples do relevo; 
- Utilização de software para a digitalização da carta geomorfológica;

- Levantamento fotográfico para registrar as morfologias do relevo, os impactos e as formas tecnogênicas encontradas;

- Aplicação de entrevistas e posterior organização e tabulação dos dados, além da elaboração de gráficos no Excel®.

\section{Métodos}

Para a realização desta pesquisa procuramos utilizar o método do materialismo histórico e dialético, que segundo Nunes et al (2006, p.125) "é um dos métodos de pensamento que tem influência na busca da articulação entre as diversas áreas da Geografia". Este método implica em não haver separação entre a relação sociedade e natureza, ou seja, a história da natureza e a história dos homens. Desta forma há a ligação entre os processos de apropriação e de transformação da natureza executadas pelos homens.

Seguindo este raciocínio e relacionando com o período técnico-científico e informacional, os estudos da dinâmica da sociedade e da natureza que estão sendo realizados pela Geografia propõem que as transformações das paisagens sejam realizadas a partir das relações histórico-dialéticas (NUNES, 2002).

Este método nos permite analisar a paisagem por meio da história de sua constituição e nos proporciona entender os processos naturais e antrópicos que atuaram na sua esculturação, isso graças ao processo histórico analisado.

A partir deste método procuramos analisar as relações homem e natureza, no momento de apropriação dos compartimentos geomorfológicos e os efeitos e respostas do ambiente. Assim foi possível identificar os diversos impactos gerados por esta dinâmica, além de compreender as intervenções realizadas na dinâmica hídrica e nos processos geomorfológicos que resultaram nas formações tecnogênicas.

Considerando-se os elementos descritos anteriormente, para a análise da paisagem e a construção da carta geomorfológica utilizou-se o primeiro nível de abordagem proposto por Ab' Saber (1969, p. 1-23). 
Este nível é identificado como "A Compartimentação Topográfica da Paisagem". Por meio dele foi possível entender a compartimentação topográfica regional, assim como realizar a caracterização e a descrição, das formas de relevo de cada um dos compartimentos (AB' SABER, 1969, p. 1-2).

A carta geomorfológica foi compartimentada em três formas: as áreas de topos, as áreas de vertentes e as áreas de fundos de vale para posterior caracterização de cada uma destas áreas.

\section{OBJETIVO}

Com o objetivo de contribuir para esta discussão, apresenta-se a seguir um esforço de aproximação da teoria à prática, por meio do estudo do bairro Jardim Humberto Salvador, localizado na zona norte da cidade de Presidente Prudente/SP. O bairro apresenta várias formações tecnogênicas que são resultantes do modo de vida da sociedade (no momento de produzir o espaço) e conseqüentemente interferem direta ou indiretamente na qualidade de vida dos moradores do bairro.

O ambiente tecnogênico no Jardim Humberto Salvador foi e continua sendo formado por uma série de fatores que estão ligados à infra-estrutura e ao modo de vida da própria população. Mas antes de avançarmos, faz-se necessária a caracterização geomorfológica da área para uma melhor compreensão do cenário ambiental deste estudo.

\section{CARACTERIZAÇÃO GEOMORFOLÓGICA E SOCIAL DA ÁREA DE ESTUDO}

O loteamento Jardim Humberto Salvador foi implantado em 1995 (JESUS, 2005) onde foram doados 1668 lotes, por meio do Projeto de Loteamentos Urbanizados, cujo objetivo primordial foi atender as famílias que ainda não haviam sido beneficiadas pelo Programa de Desfavelamento implementado na zona leste de Presidente Prudente, no final da década de 80.

O Loteamento ocupa dois tipos de compartimentos geomorfológicos (figura 1): os topos e as vertentes. 
FIGURA 01. CARTA GEOMORFOLÓGICA DO JARDIM HUMBERTO SALVADOR.

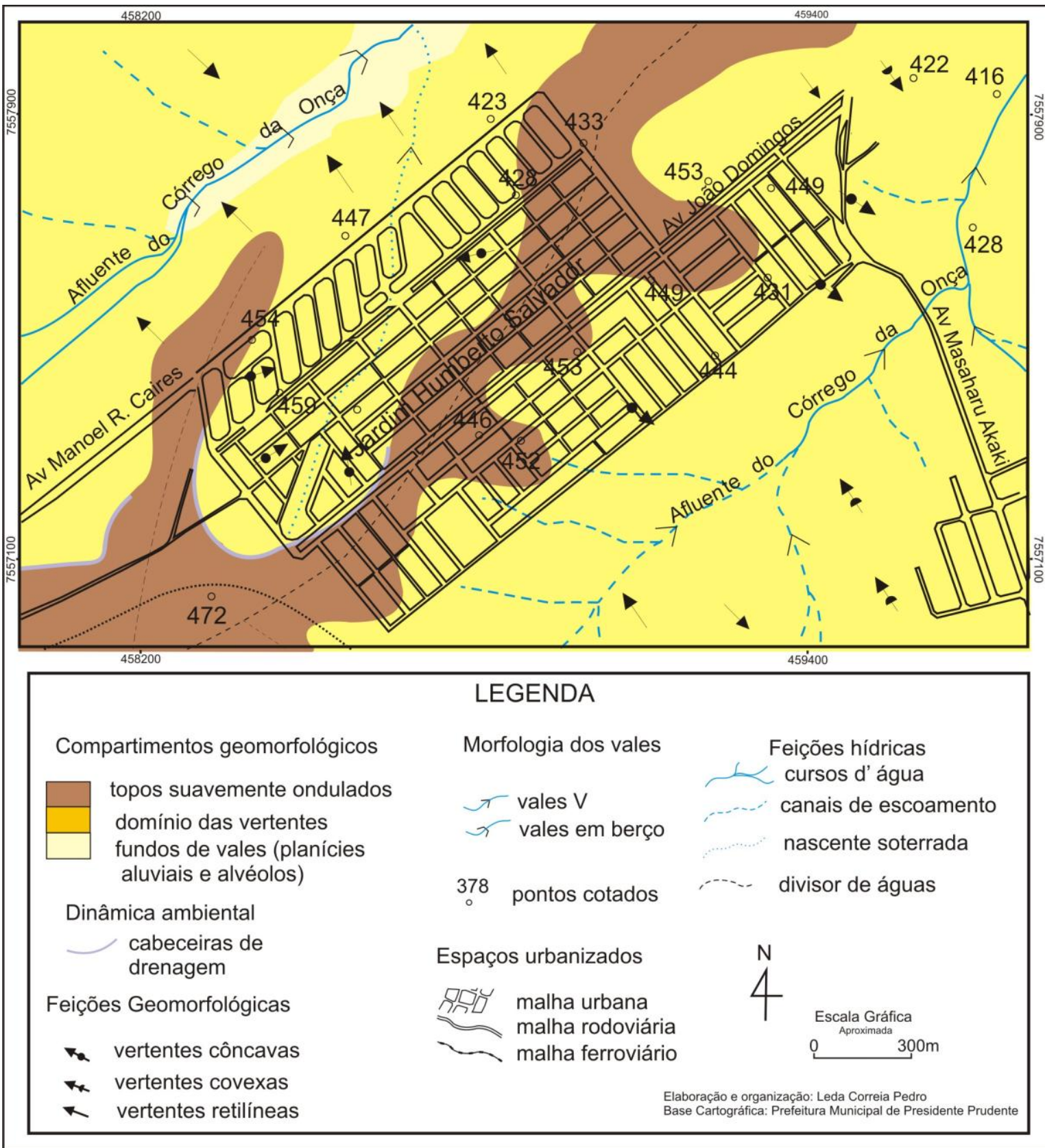

Os topos apresentam-se suavemente ondulados e correspondem ao divisor de água das bacias do rio Santo Anastácio e Mandaguari. Este compartimento possui uma morfologia que favoreceu a ocupação, pois apenas alguns pontos do loteamento precisaram de obras de engenharia específicas para terrenos íngremes, como a terraplenagem, o corte de taludes etc.

No compartimento das vertentes, encontramos a maior parte do loteamento. Neste caso a implantação do loteamento se iniciou nas áreas de topos e se 
expandiu para as altas e médias vertentes que estão classificadas em retilíneas, côncavas e convexas. Estas morfologias necessitam de cuidados específicos para implantação de um loteamento, pois são necessárias obras de terraplenagem que envolvem cortes no relevo, além da necessidade de construção de muros de arrimo para se evitar o desmoronamento do talude etc.

As altitudes encontradas no loteamento variam entre 425 a $455 \mathrm{~m}$ e as declividades constatadas em alguns locais chegam a alcançar 30\%, já o declive predominante é de $20 \%$.

As morfologias dos fundos de vale apresentam-se em $\mathrm{V}$ e em berço. Nas formas em $V$ encontramos cursos d' água, protegidos com mata ciliar. Já os vales em berço, apresentam-se com resquícios de vegetação de pequeno porte, com bancos de areia no curso d'água. Neste tipo de vale encontramos algumas planícies aluviais.

Todas as características geomorfológicas são importantes no momento de instalação de um loteamento, principalmente se envolver uma parte da população carente, que não tem condições de construir obras de engenharia adequada para garantir qualidade de vida.

O levantamento histórico de apropriação e ocupação do Jardim Humberto Salvador apontou que, os agentes que produziram este espaço urbano foram os setores público e o privado.

A prefeitura municipal representou o setor público que contribuiu com a aprovação do loteamento, e que inclusive realizou a terraplenagem do local e as obras necessárias para a instalação do mesmo. Além disso, o setor privado, representado pelos moradores do loteamento (de forma mais organizada e engajada, por meio da associação de moradores) atuou para conquista de infraestruturas, como asfalto, linhas de ônibus, rede de esgoto e de distribuição de água etc.

Os dados coletados no campo mostraram que o Jardim Humberto Salvador possui uma população de baixo poder aquisitivo (Figura 2), em que $60 \%$ dos entrevistados possuem uma renda mensal de um a dois salários mínimos, 28\% recebem de três a cinco salários, $9 \%$ conquistam com seu trabalho apenas um 
salário, $2 \%$ estão no momento sem renda e $1 \%$ da população entrevistada recebem ao mês mais de seis salários mínimos.

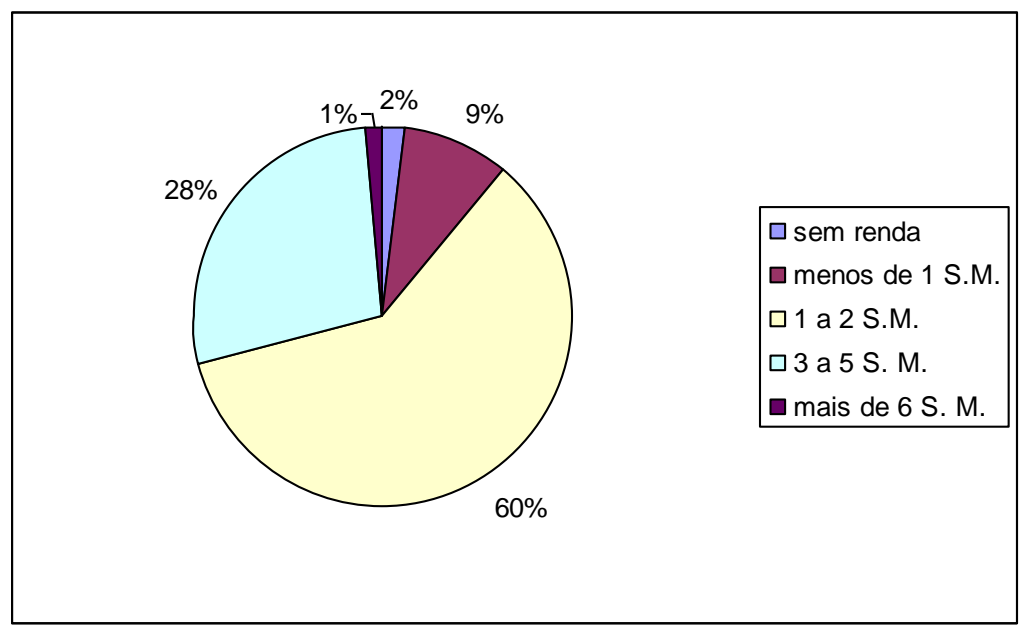

O loteamento foi implantado em uma área com declividades acentuadas. Os percentuais acima mostram que $60 \%$ da população que ocupa estes compartimentos geomorfológicos possuem uma renda mensal em torno de dois salários mínimos e são classificados de acordo com o CEMESPP $(1997)^{5}$ como áreas de exclusão social. Estes compartimentos geomorfológicos possuem declividades elevadas, que atingem o intervalo de 20 a $30 \%$

De acordo com os estudos realizados por Pedro (2005 e 2008) quando analisado o histórico de ocupação da cidade de Presidente Prudente, percebe-se que os compartimentos geomorfológicos com declividades mais acentuadas estão ocupados por uma população de baixa renda (o caso da zona leste, norte etc.). Por outro lado, os compartimentos com morfologias mais suaves ou planas (oeste, sul) são destinados à população com um alto poder aquisitivo.

\footnotetext{
${ }^{5}$ Os estudos sobre exclusão social são realizados pelo grupo de pesquisa CEMESPP (Centro de Estudos sobre Mapeamento da Exclusão Social para Políticas Públicas). O grupo busca construir, desenvolver, aplicar e avaliar metodologias e tecnologias de mapeamento e análise de processos de exclusão social nas cidades de porte médio.
} 
Essa dinâmica de ocupação decorre principalmente das ações dos agentes de produção do espaço urbano ${ }^{6}$, envolvendo tanto o setor público quanto o setor privado. Somente a título de exemplo, na zona leste de Presidente Prudente, onde o relevo é mais acidentado (SPOSITO, 1983), a concentração de bairros classificados como áreas de exclusão social são expressivos, sendo que nas zonas sul e oeste, onde o relevo é mais suave, predominam as áreas de inclusão.

Outro aspecto social importante do bairro está relacionado ao número de pessoas residentes em cada domicílio (Figura 03). Exatamente $55 \%$ das famílias são compostas por três e quatro integrantes. Já $20 \%$ responderam que residem na casas até duas pessoas e $25 \%$ das entrevistas apontaram que residem na casas mais de cinco pessoas.

FIGURA 03. NÚMERO DE MORADORES POR DOMICÍLIO - 2007

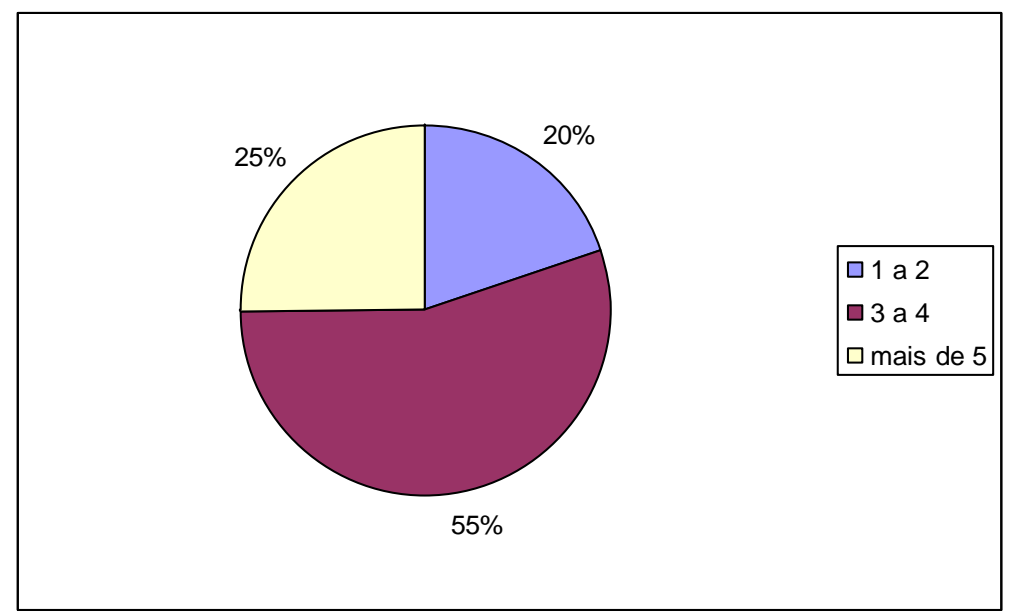

Verificou-se que $80 \%$ dos questionários relataram que os moradores do Jardim Humberto Salvador possuem famílias compostas por mais de três pessoas. Sendo que $55 \%$ apontaram que as famílias são compostas por três a quatro membros e $25 \%$ dos entrevistados responderam que suas famílias são constituídas por mais de cinco integrantes. Já os $20 \%$ restante, responderam que suas famílias são constituídas por uma ou duas pessoas, número de pessoas compatível ao tamanho do lote e as residências.

\footnotetext{
${ }^{6}$ Os agentes são: os proprietários dos meios de produção (sobretudo os grandes industriais), os proprietários fundiários, os promotores imobiliários, o Estado e os grupos sociais excluídos (CORRÊA, 1989, p.8).
} 
No entanto, ao relacionar estes dados com o tamanho dos lotes doados (Tabela 01) pode-se concluir que os lotes são pequenos para as famílias constituídas por mais de três integrantes.

TABELA 01. DADOS REFERENTES AO TAMANHO DOS LOTES

\begin{tabular}{|l|l|}
\hline \multicolumn{2}{|l|}{} \\
\hline Maior lote residencial & $230,59 \mathrm{~m}^{2}$ \\
\hline Menor lote residencial & $132,63 \mathrm{~m}^{2}$ \\
\hline
\end{tabular}

Fonte: Secretaria de Planejamento - Prefeitura Municipal de Presidente Prudente, 2002.

Os moradores do Jardim Humberto Salvador passaram a conviver com problemas socioambientais decorrentes desta alta densidade de ocupação.

A população do bairro enfrentou muitos problemas relacionados aos períodos de chuva, principalmente em relação à infra-estrutura. Os problemas identificados nos trabalhos de campo foram: os buracos nas ruas, partes do asfalto levados pelas águas pluviais (enxurrada); os muros que limitam as residências desabaram com o excesso de umidade e infiltração, interditando casas e colocando em perigo a vida dos moradores; as erosões urbanas estão presentes em vários pontos do bairro, principalmente as ravinas e as voçorocas.

A configuração geomorfológica e o modo como se produziu este loteamento está contribuindo na esculturação das áreas superficiais. A inter-relação da dinâmica sociedade e natureza na produção do espaço urbano está interferindo na dinâmica hídrica, morfológica etc. e gerando os relevos tecnogênico (formas superficiais). Diante disto, constataram-se algumas morfologias superficiais tecnogênicas, que serão abordadas no item a seguir.

\section{OS RELEVOS TECNOGÊNICOS NO JARDIM HUMBERTO SALVADOR}

As morfologias encontradas em cada compartimento do relevo, no ambiente urbano estudado, sofreram intervenções de agentes modeladores que podem ser classificados em naturais e sociais. Os naturais seriam aqueles vinculados aos fatores climáticos e sua dinâmica como a glacial, dos ventos e o intemperismo químico e físico, já que os agentes sociais estão ligados às ações da sociedade, quando se produz o espaço. 
Os trabalhos desenvolvidos por Peloggia (1998) e Fujimoto (2005) demonstram que a intervenção da sociedade na dinâmica da natureza pode causar algumas conseqüências para o ambiente, que estão divididas em três "níveis" de abordagem.

O primeiro nível trata-se da ocorrência de modificações no relevo, ou seja, na forma. O segundo refere-se a alterações na dinâmica geomorfológica, ou melhor, nos processos geomorfológicos. E por último, temos a criação de depósitos correlativos, isto é, os depósitos tecnogênicos.

Cada nível é identificado da seguinte maneira:

No primeiro nível denominado "modificação do relevo" "encontramos o surgimento de formas de relevo tecnogênico decorrentes de processos criados ou induzidos pela atividade humana" (FUJIMOTO, 2005, p.78). É possível identificar neste nível, as menores configurações produzidas pelos processos morfogenéticos atuais e quase sempre induzidos pela ação humana. Exemplo: a) os sulcos erosivos; b) os cones de dejeção tecnogênicos e c) as cicatrizes de solapamento.

Neste nível, também é possível identificar pequenas formas de relevo decorrentes da interferência antrópica ao longo das vertentes, como os cortes e os aterros. Já em relação as conseqüências desta interferência destacamos as planícies tecnogênicas (FUJIMOTO, 2005).

No segundo nível conhecido pela "modificação dos processos geomorfológicos" e o surgimento de "novos padrões morfodinâmicos", promovem a criação, a indução e a intensificação destes processos. Como exemplo, podemos citar algumas atividades antrópicas que geram estes novos compartimentos, a) a eliminação da cobertura vegetal (cortes e aterros); b) os arruamentos; c) a impermeabilização; d) as canalizações, e) os aterros.

O terceiro nível é marcado pela "criação de depósitos correlativos representados pelos depósitos tecnogênicos". "Esses depósitos evidenciam um ciclo de erosibilidades sobre a massa erodível (AB' SABER, 1990 in: PELOGGIA, 1998). Os depósitos tecnogênicos são correlativos aos processos relacionados às formas humanas de apropriação do relevo e sua época de existência caracteriza um tempo geológico/histórico distinto" (FUJIMOTO, 2005, p. 78). 
De acordo com a classificação de Peloggia e Fujimoto, foram identificados na paisagem da área de estudo os três níveis de abordagem.

No primeiro nível identificaram-se vários estágios do processo erosivo que são os sulcos, as ravinas e as voçorocas.

Estas formas erosivas são provocadas pela inter-relação entre a dinâmica da natureza (que sofre intervenção) e da dinâmica da sociedade (que intervém no ambiente natural).

Os processos erosivos foram provocados por um conjunto de elementos da dinâmica da sociedade, no qual se incluem a impermeabilização do solo, a concentração das águas pluviais, a retirada da cobertura vegetal, entre outros.

A concentração de águas pluviais em determinados pontos do bairro, junto com o fator declividade e a aceleração da velocidade do escoamento superficial, provocaram nas vertentes e nos fundos de vale processos erosivos como observados nas fotos 01 e 02.

\section{FOTO 01. PROCESSO DE RAVINAMENTO PROVOCADO PELA GRANDE CONCENTRAÇÃO DE} ÁGUAS PLUVIAIS.

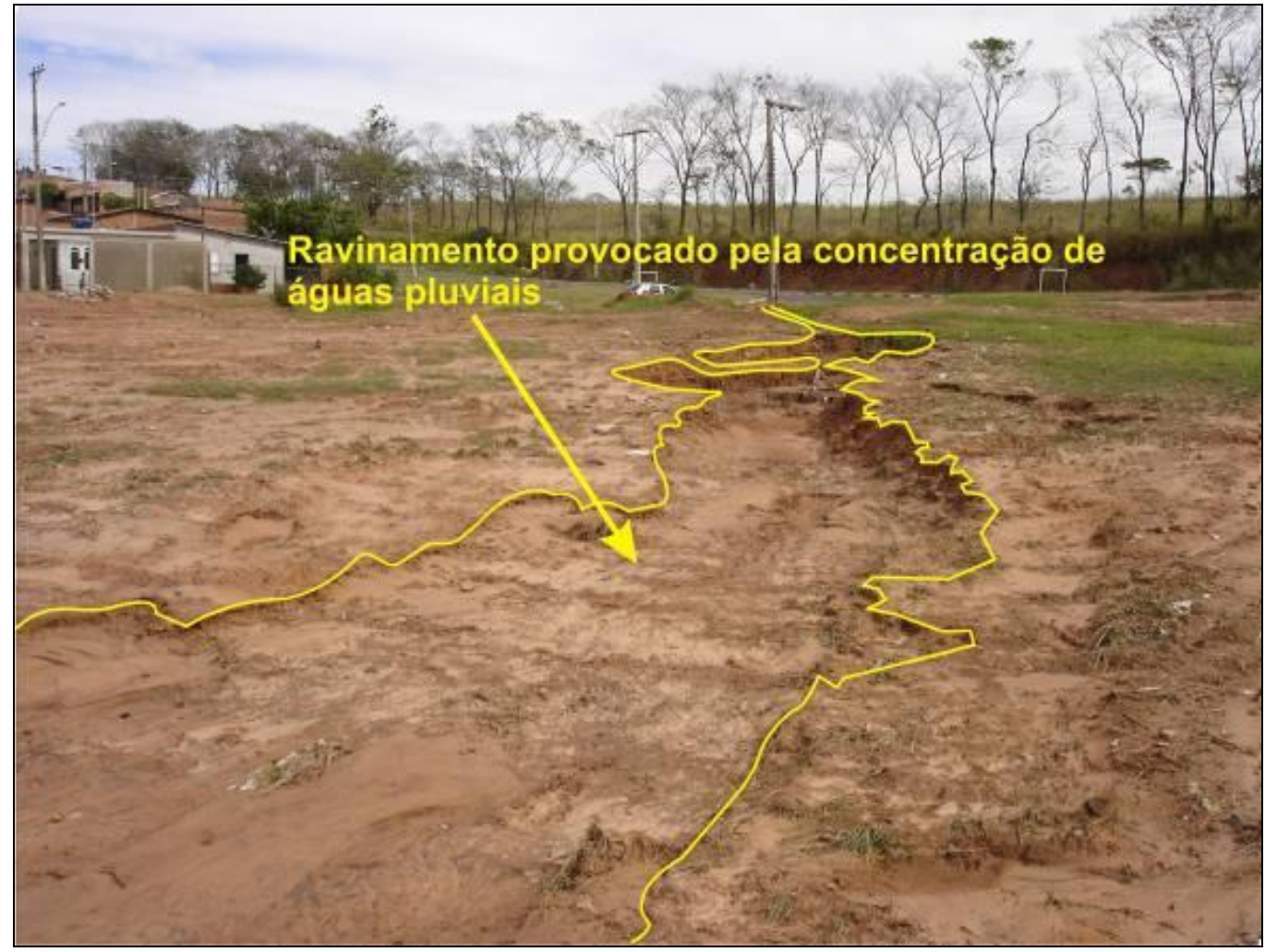

Fonte: trabalho de campo- 2008. 
FOTO 02. NO PRIMEIRO ESTÁGIO DO PROCESSO EROSIVO, OBSERVAM-SE PEQUENOS SULCOS NO SOLO, PROVOCADO PELO ESCOAMENTO SUPERFICIAL EM SOLO EXPOSTO.

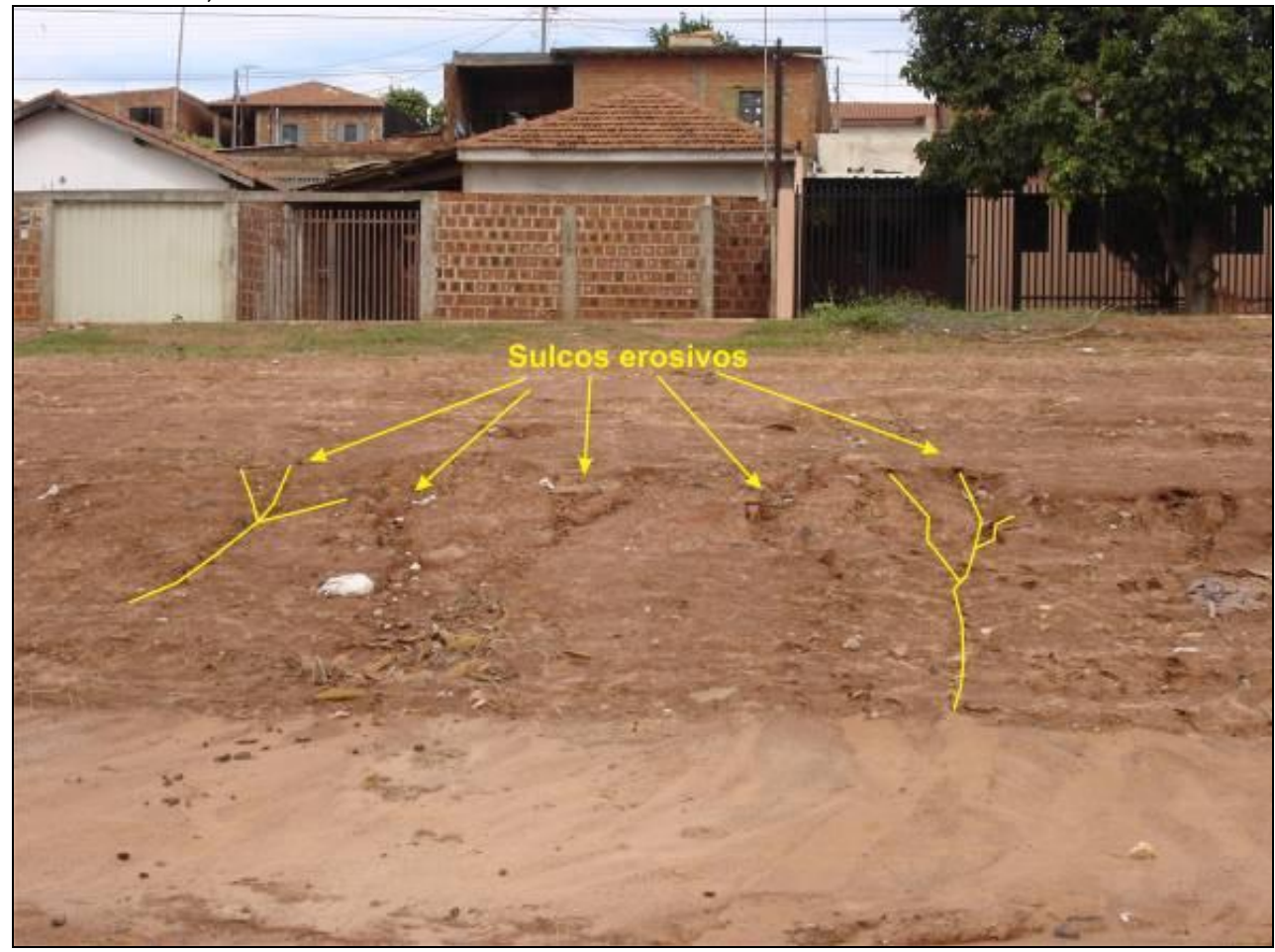

Fonte: Trabalho de Campo- 2008.

Nas fotos 01 e 02 foram identificados os dois primeiros estágios do processo erosivo no Jardim Humberto Salvador. Como as áreas de topos foram totalmente ocupadas por residências e o solo impermeabilizado (maior parte do topo), as águas pluviais não infiltraram. Isto provocou e intensificou o aumento do escoamento superficial pelas ruas. A rede de captação de águas pluviais não conseguiu absorver todo o volume d' águas direcionado a ela, o que acabou gerando impactos em alguns pontos do bairro.

As bocas de lobos não conseguem absorver parte das águas pluviais que escoam ao longo das vertentes urbanizadas e acabam sendo destruídas pela força do escoamento superficial (foto 03 e 04 ).

As vertentes com morfologias convexas acabam contribuindo na formação de processos erosivos. Estas formas dispersam as águas pluviais e originam pequenos canais de escoamento que levam consigo sedimentos para os compartimentos mais baixos. As morfologias côncavas tendem a concentrar estas águas promovendo a infiltração das mesmas, contribuindo para o abastecimento do aqüífero freático das proximidades. 
FOTO 03. A CONCENTRAÇÃO DE ÁGUAS PLUVIAIS É O RESULTADO DA INTERVENÇÃO DA DINÂMICA DA SOCIEDADE NO AMBIENTE NATURAL. AS RUAS SUPERFÍCIES IMPERMEÁVEIS ACELERAM A VELOCIDADE DO ESCOAMENTO RETIRANDO PARTE DA COBERTURA ASFÁLTICA.

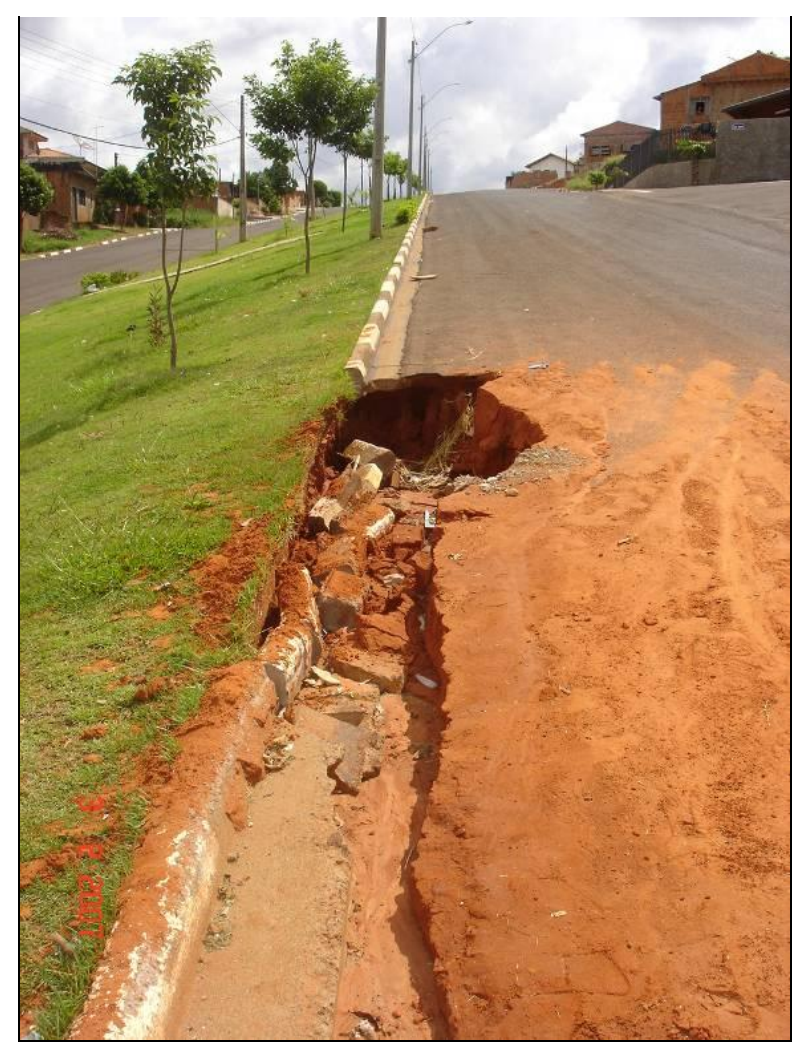

Fonte: Trabalho de Campo- 2008.
FOTO 04. A INTERVENÇÃO SOCIAL NA DINÂMICA HÍDRICA, OU SEJA, A SOCIEDADE REDIRECIONANDO OS FLUXOS DE ESCOAMENTO ACABA CONCENTRANDO ÁGUA EM DETERMINADOS LOCAIS, NÃO ESQUECENDO QUE O FATOR IMPERMEABILIZAÇ̃̃O ACABA CONTRIBUINDO COM O AUMENTO DE VOLUME DE ÁGUA.

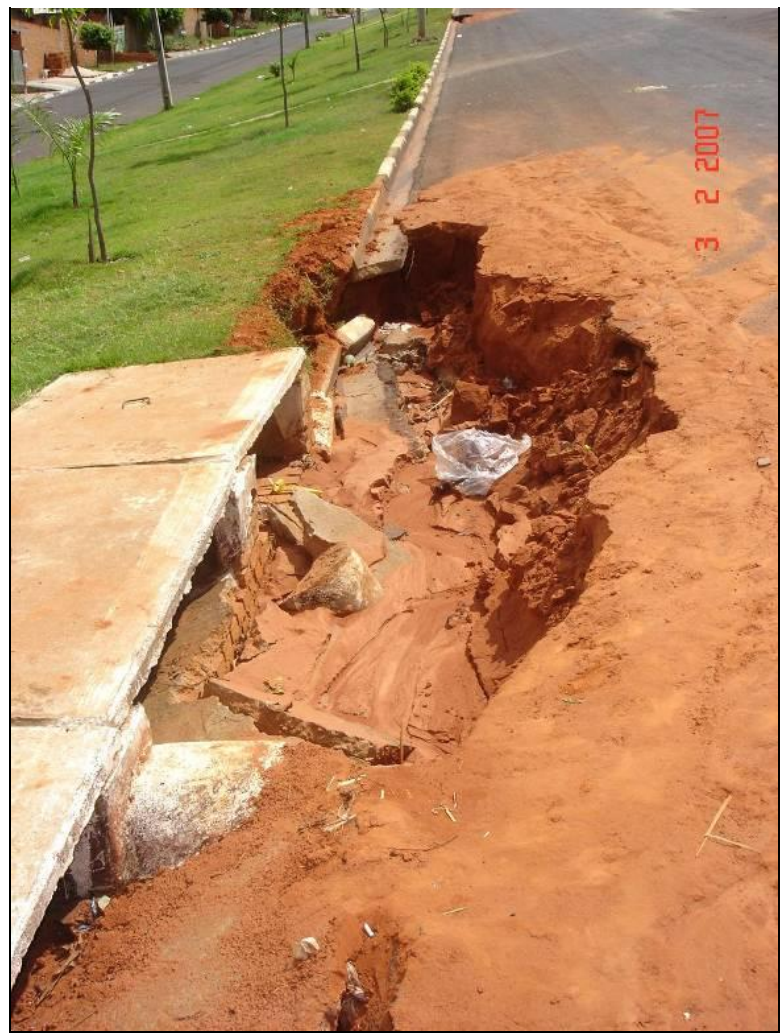

Nas áreas adjacentes ao Jardim Humberto Salvador localizou-se em uma das vertentes o estágio mais avançado do processo erosivo, o voçorocamento do solo. A voçoroca encontrada passou a ser utilizada pela população local como área de deposição de resíduos sólidos, como se observa nas fotos 05 e 06 . 
FOTO 05. VOÇOROCA EM ESTÁGIO MAIS AVANÇADO DO PROCESSO EROSIVO.

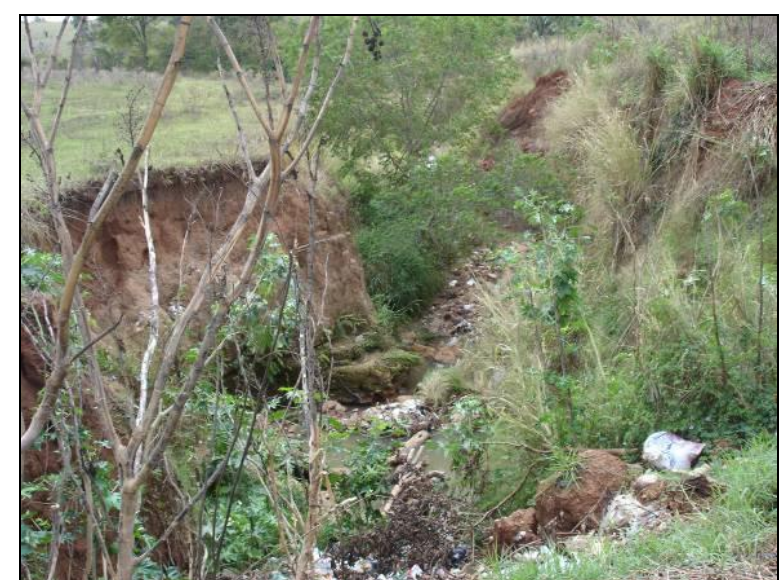

Fonte: Trabalho de Campo- 2007
FOTO 06. AS VOÇOROCAS ACABAM SENDO UTILIZADAS PELA POPULAĈ̃O LOCAL COMO LOCAL DE DEPOSITO DE RESÍDUOS (LIXO).

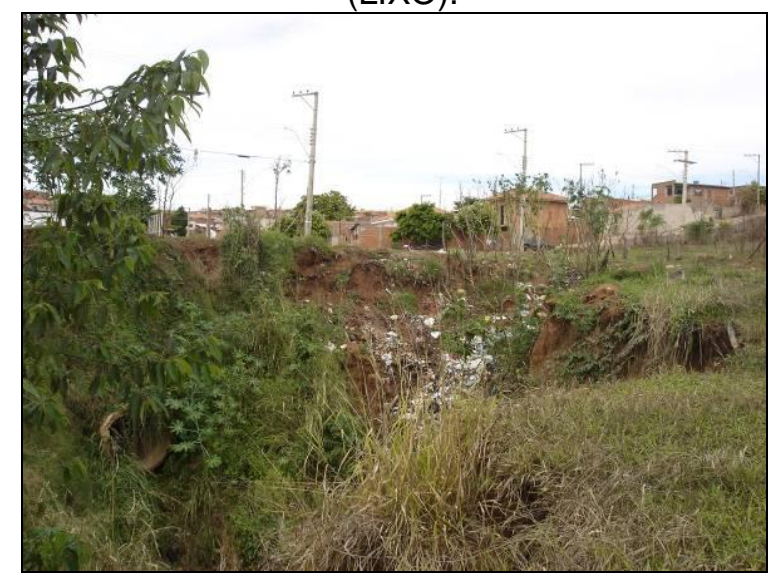

Estas formas erosivas estão vinculadas à ocupação do relevo que não respeita as dinâmicas hídricas, pedológicas, geomorfológicas etc.

As alterações das morfologias dos topos, das vertentes e dos fundos de vale foram provocadas por diferentes atividades sociais. Estas atividades são responsáveis por gerarem novos padrões de comportamento morfodinâmicos e geomorfológicos, e contribuem na formação de relevos tecnogênicos. Dentre as atividades sociais ligadas às dinâmicas naturais destacam-se a eliminação de cobertura vegetal (solo exposto), os arruamentos (impermeabilização) e os aterros.

O solo exposto é o resultado da retirada da cobertura vegetal, desta forma o ciclo hidrológico sofre uma alteração em sua dinâmica natural. As águas pluviais que antes encontravam na cobertura vegetal um obstáculo (tinham a função de diminuir o impacto das gotículas de chuva diretamente com o solo, impedindo o efeito "splash", e permitindo a infiltração desta água no solo) no momento atual não encontra vegetação alguma. $O$ que encontramos na área de estudo são lotes edificados e pastagens nas áreas adjacentes.

Desta forma, tem-se uma alteração da geometria dos compartimentos geomorfológicos. As vertentes sofrem um aumento em seus declives, principalmente com os cortes destinados às ruas ou com os nivelamentos do terreno para a edificação dos lotes. 
O solo exposto (foto 07 ) está fragilizado e pode gerar uma série de processos erosivos como destacados anteriormente.

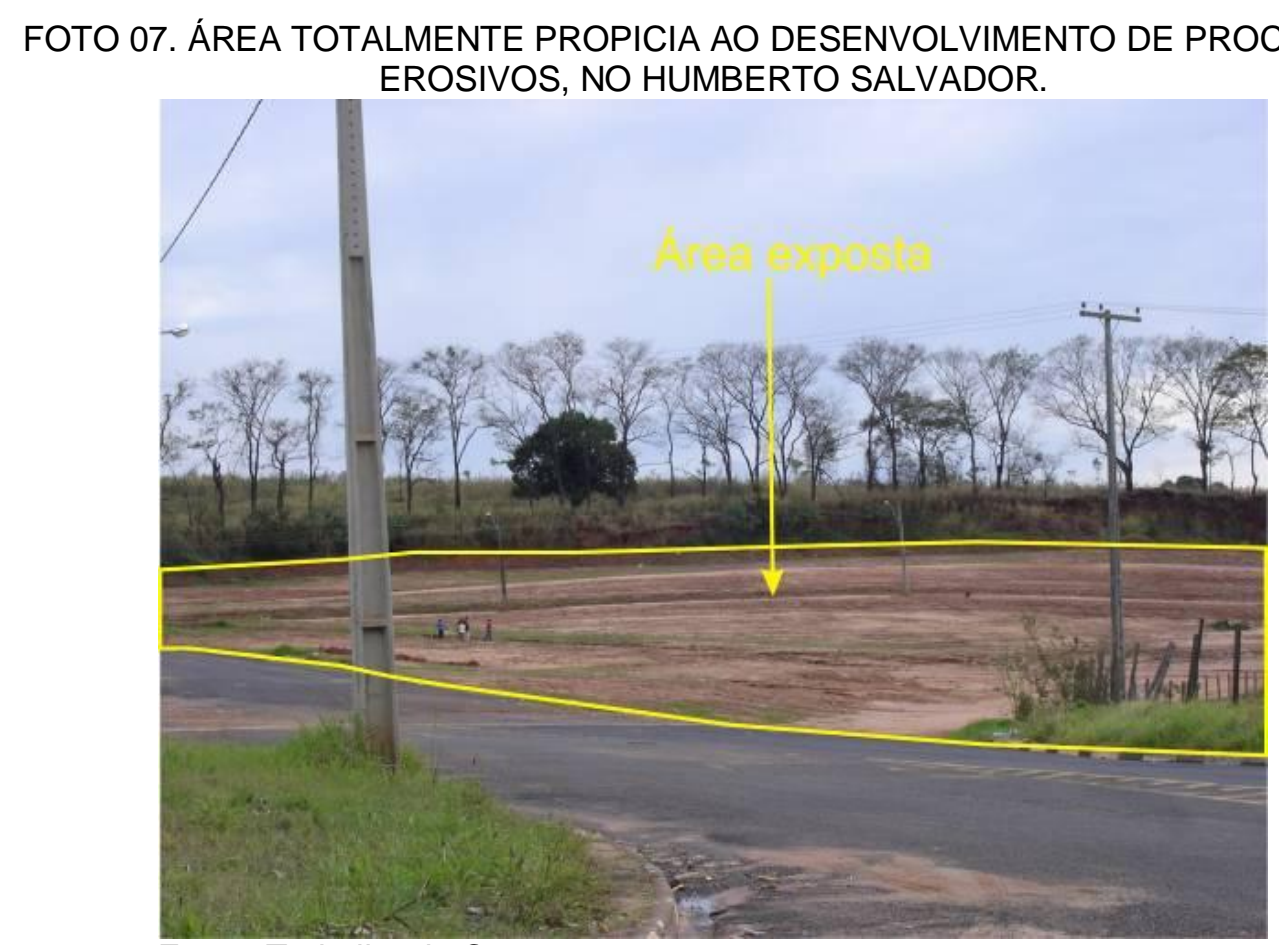

Fonte: Trabalho de Campo- 2008.

Outra atividade social que contribui na formação de relevos tecnogênicos são os arruamentos associados às declividades das vertentes.

As ruas de um loteamento, mesmo respeitando o declive dos compartimentos geomorfológicos, acabam interrompendo os fluxos hídricos e gerando novos padrões de drenagem. Essas ruas são transformadas em leitos pluviais que, nos períodos de chuvas intensas, acabam canalizando e direcionando o sistema de drenagem para determinadas áreas. Diante deste fato, a infiltração das águas da chuva no solo fica comprometida, pois o ciclo hidrológico neste ambiente urbano sofre alteração. Esta intervenção acaba alterando toda a dinâmica existente nesta área.

As declividades nos arruamentos (foto 08 ) acabam acelerando a velocidade do escoamento superficial das águas pluviais, transportando sedimentos, resíduos etc., sendo que, ao serem levados por estas águas, acumulam-se nas áreas mais baixas. A acumulação ocasiona transtornos à população, como no caso dos resíduos 
sólidos domésticos que entopem as bocas de lobo nas áreas baixas dos compartimentos e acabam invadindo os lotes de alguns moradores. Além disso, ocasiona o assoreamento dos cursos d'água.

FOTO 08. DECLIVIDADE ACENTUADA EM UMA DAS RUAS DO JARDIM HUMBERTO SALVADOR, A PARTE INFERIOR DA RUA (BAIXA VERTENTE URBANIZADA) ESTÁ COM ACUMULO DE SEDIMENTOS ORIUNDOS DOS TOPOS.

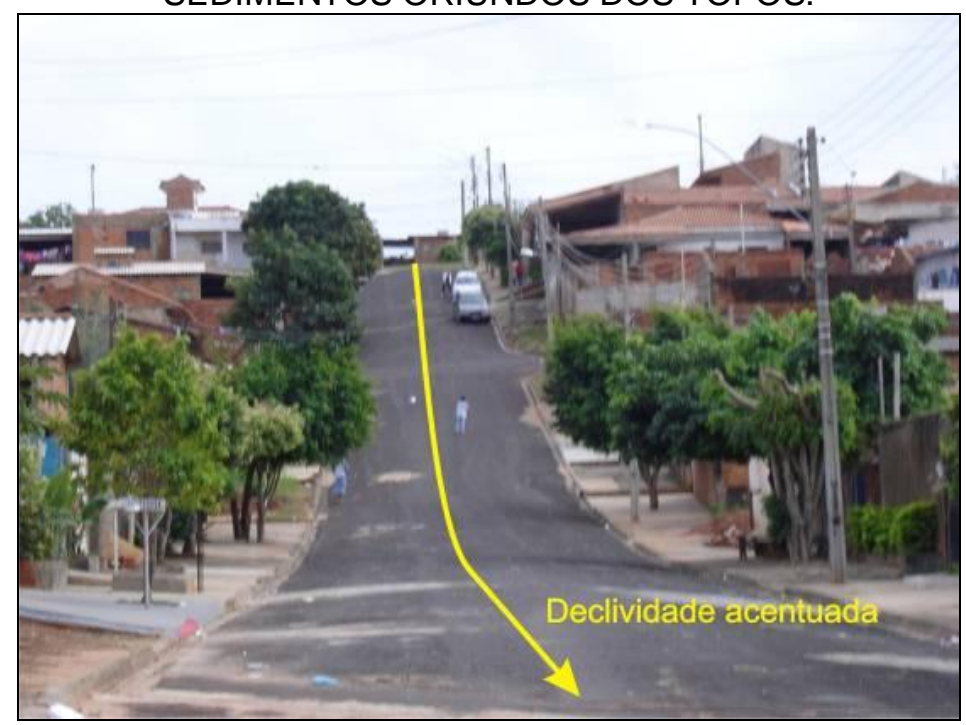

Fonte: Trabalho de Campo-2007

Por último destacam-se os aterros e os depósitos, ambos resultantes das atividades sociais e contribuem na formação dos relevos tecnogênicos. Os aterros e os depósitos, segundo Peloggia et al (2005) podem ser constituídos de duas maneiras: por intervenção direta ou indireta da ação da sociedade.

Os aterros (foto 09 e 10) são formações construídas a partir dos processos de acumulação de sedimentos, da deposição de terra oriunda de outros lugares, de entulho (resto de materiais de construção), de lixo (resíduos sólidos) etc. Estes diferentes materiais constituem uma camada superficial diferenciada e podem ser denominados de aterros tecnogênicos. 
FOTO 09. A PRIMEIRA FOTO FAZ PARTE DO SISTEMA DE CAPTAÇÃO DE ÁGUAS PLUVIAIS DO HUMBERTO SALVADOR. NO PERÍODO DE CHUVAS OCORRE UMA GRANDE CONCENTRAÇÃO DE ÁGUA NESTA ÁREA, LOCALIZADO NO FUNDO DO VALE.

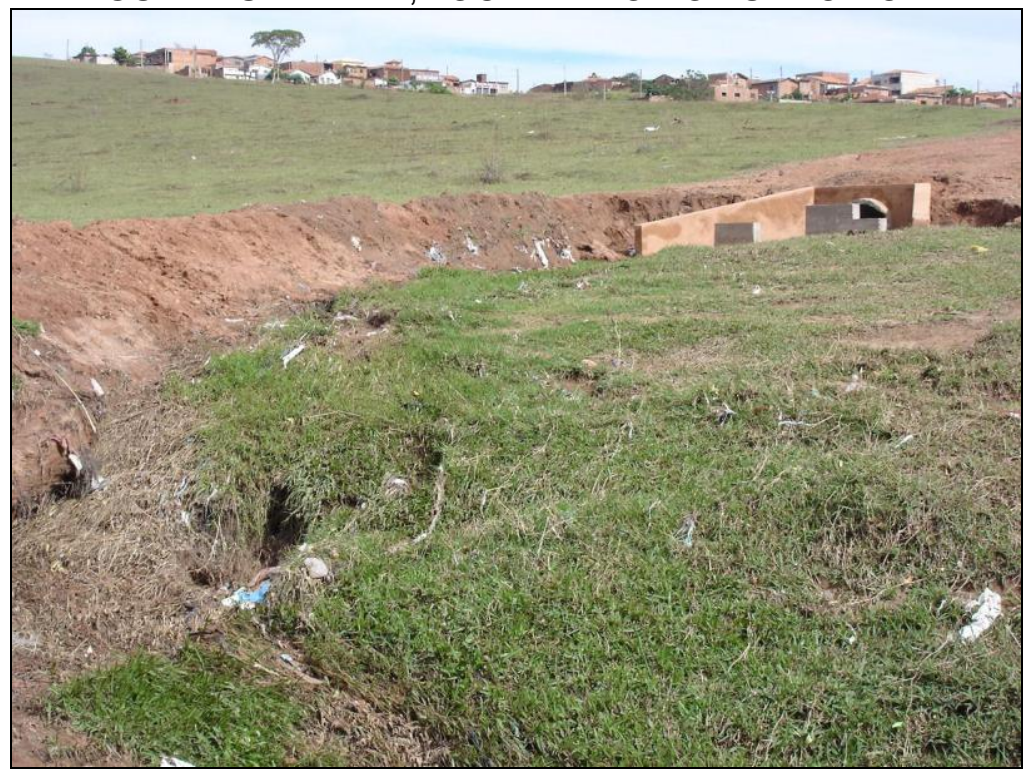

Fonte: Trabalho de Campo-2008.

FOTO 10. ATERRO FORMADO POR RESÍDUOS SÓLIDOS. O CURSO D' ÁGUA DESTE VALE ESTÁ SOFRENDO UM INTENSO PROCESSO DE SOLAPAMENTO. A FOTO 09 MOSTRA COMO A INTENSA TORRENTE (FRUTO DO DIRECIONAMENTO DOS FLUXOS HÍDRICOS DE PARTE DO BAIRRO) ESTÁ EXPONDO O LIXO DEPOSITADO NESTE COMPARTIMENTO.

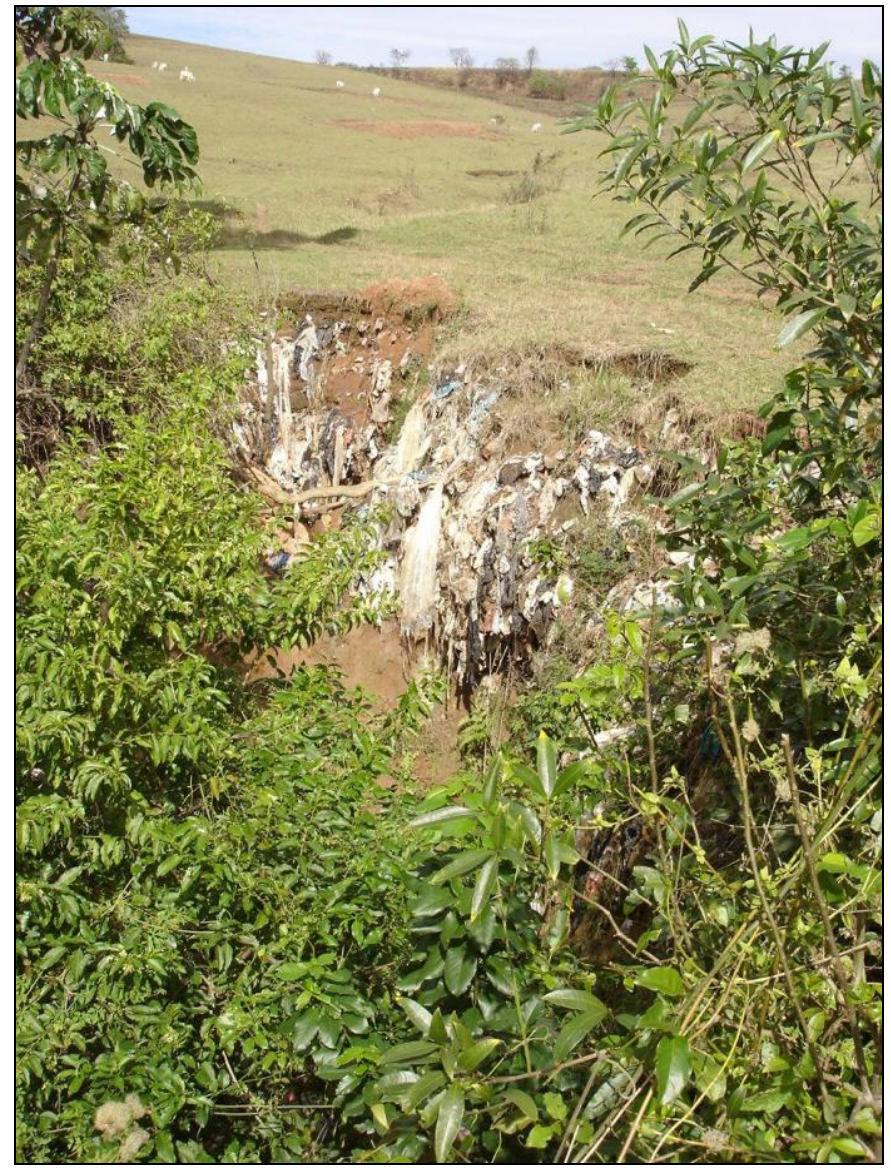

Fonte: Trabalho de Campo-2008. 
Os depósitos tecnogênicos são formações decorrentes da acumulação de materiais úrbicos, de resíduos sólidos e de sedimentos. Estes podem ser encontrados com mais freqüência a jusante das vertentes e nos fundos de vale.

As planícies tecnogênicas são exemplos dessas formas deposicionais. As áreas planas dos fundos de vale (foto 11) são compartimentos propícios a acumulação de sedimentos e outros tipos de materiais de origem antropogênica. As dinâmicas de deposição e acumulação contribuem para agravar o quadro dos processos degradativos dos cursos d'água no ambiente urbano.

Os relevos de origem tecnogênicos são resultados do momento histórico atual, no qual a sociedade interfere na dinâmica da natureza de forma expressiva e com uma intensidade, que acabam modificando a dinâmica natural dos processos geomorfológicos.

\section{FOTO 11. O CURSO D' ÁGUA LOCALIZADO NAS ADJACÊNCIAS DO JARDIM HUMBERTO SALVADOR POSSUI ÁREAS COM PLANÍCIES TECNOGÊNICAS. HÁ UMA ÁREA RELATIVAMENTE PLANA COM ACÚMULO DE MATÉRIAS ÚRBICOS E SEDIMENTOS, CARACTERIZANDO ASSIM ESTÁ NOVA FORMAÇÃO DECORRIDA DAS DINÂMICAS DA} SOCIEDADE E DA NATUREZA.

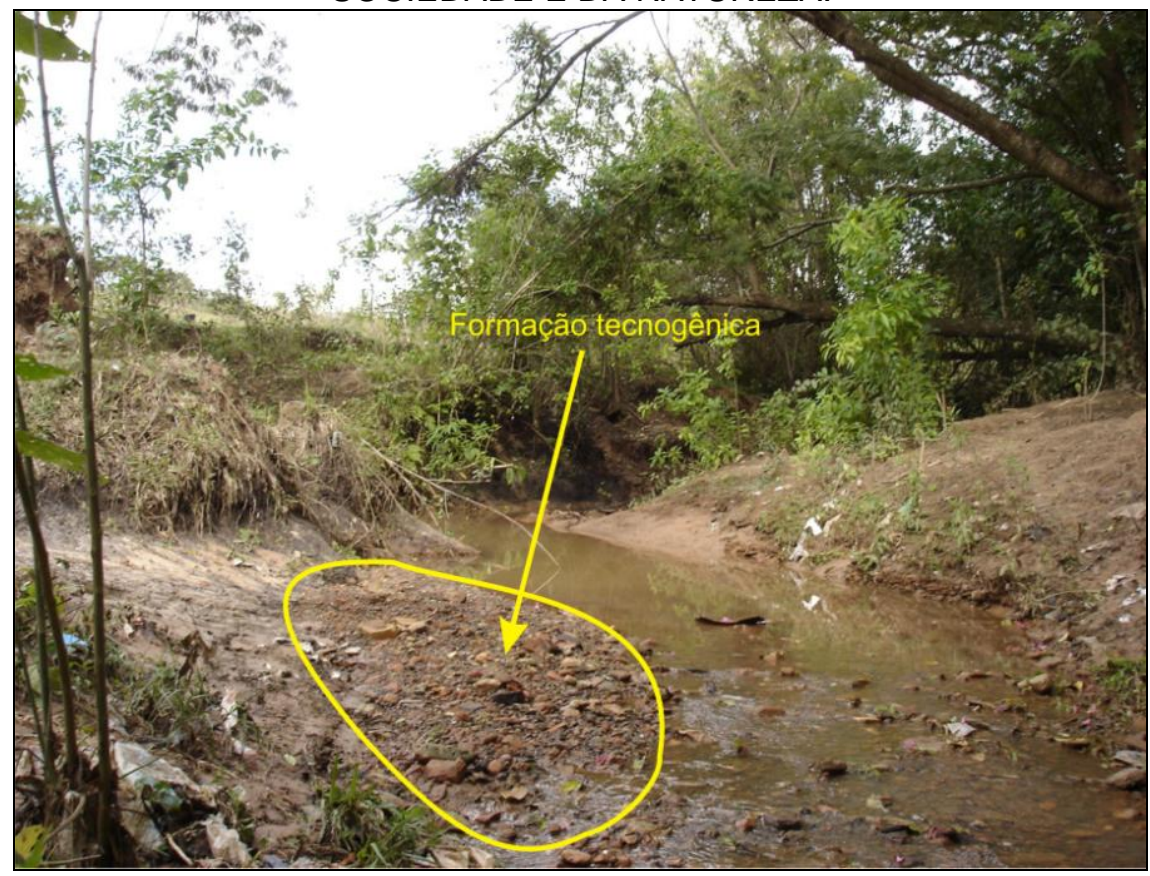

Fonte: Trabalho de Campo- 2007

Assim, como resultados, temos uma paisagem antropogênica, no qual se identificam as intervenções da sociedade como relatados anteriormente no Jardim Humberto Salvador. 


\section{CONSIDERAÇÕES FINAIS}

Com base nesta pesquisa que enfoca o processo de apropriação e ocupação dos compartimentos geomorfológicos em áreas urbanas e os impactos gerados, foi possível demonstrar alguns dos principais efeitos e respostas do ambiente urbano, decorrentes da implantação do loteamento Jardim Humberto Salvador.

A dinâmica da sociedade está alterando a dinâmica natural dos processos geomorfológicos do Jardim Humberto Salvador. Desta forma, a dinâmica social está contribuindo na intensificação dos processos de esculturação das vertentes, que por sua vez ocasiona a mudança dos padrões de escoamento e permeabilidade das águas pluviais e o carregamento de sedimentos para os vales.

Esta dinâmica que envolve a sociedade e a natureza está intensificando os processos erosivos e deposicionais na área de estudo. Assim temos a criação de novas formas de relevos, como os tecnogênicos, cuja origem está ligada à atuação da sociedade ao produzir o espaço. Desta forma encontramos áreas com um elevado comprometimento socioambiental, no que se refere à qualidade de vida das pessoas que estão residindo em locais com esta dinâmica de produção.

\section{REFERÊNCIAS}

CEMESPP. Atlas de ExIcusão e Inclusão Social de Presidente Prudente. FCTUnesp, 1997.

CORRÊA, Roberto Lobato. O espaço urbano. São Paulo: Editora Ática, 1989.

FUJIMOTO Nina Simone Vilaverde Moura. Considerações sobre o ambiente urbano: um estudo com ênfase na geomorfologia urbana. São Paulo: Revista do Departamento de Geografia, 2005.

JESUS, Patrícia Maria de. "Produção do espaço urbano no Jardim Humberto Salvador, Presidente Prudente /SP. Afastamento, Exclusão ou Segregação socioespacial?". Monografia de Bacharelado. 2005. Faculdade de Ciências e Tecnologia, Universidade Estadual Paulista, Presidente Prudente.

PEDRO, Leda Correia. O estudo das diferentes formas de ocupação das vertentes: o caso dos bairros Vila Aurélio, Vila Rotary, Jardim Cambuci, Jardim Paraíso e Parque José Rotta. Monografia de Bacharelado. 2005. Faculdade de Ciências e Tecnologia, Universidade Estadual Paulista, Presidente Prudente. 
PEDRO, Leda Correia. Ambiente e Apropriação dos Compartimentos Geomorfológicos do Conjunto Habitacional Jardim Humberto Salvador e do Condomínio Fechado Damha- Presidente Prudente/SP. Dissertação de Mestrado. 2008. Faculdade de Ciências e Tecnologia, Universidade Estadual Paulista, Presidente Prudente/SP.

PELOGGIA, Alex. O homem e o ambiente geológico: geologia, sociedade e ocupação urbana no Município de São Paulo. São Paulo: Xamã, 1998.

OLIVEIRA, A M S ; BRANNSTROM, C ; NOLASCO, M ; PELOGGIA, A U G ; PEIXOTO, $M N$; COLTRINARI, L . Tecnógeno: registros da ação geológica do homem. In: SOUZA, C.R.G.; SUGUIO, K.; OLIVEIRA, A.M.S.; OLIVEIRA, P.E.. (org.). Quaternário do Brasil. São Paulo - Ribeirão Preto: Associação Brasileira de Estudos do Quaternário - Holos ed., 2005, v., p. 363-376.

NUNES, João Osvaldo Rodrigues; SANT'ANNA NETO, João Lima; TOMMASELLI, José Tadeu Garcia; AMORIN, Margarete Cristina da Costa Trindade; PERUSI, Maria Cristina. A influência dos métodos científicos na geografia física. Terra Livre, $v$ 2, p 121-132, 2006.

NUNES, João Osvaldo Rodrigues. Uma contribuição metodológica ao estudo da dinâmica da paisagem aplicada à escolha de áreas para construção de aterro sanitário em Presidente Prudente. Presidente Prudente, 2002. 211 f. Tese (Doutorado em Geografia) - Faculdade de Ciências e Tecnologia, Universidade Estadual Paulista).

NUNES, João Osvaldo Rodrigues ; SUERTEGARAY, D. M. A. . A natureza da Geografia Física. Terra Livre, São Paulo, v. 1, n. 16, 2001.

PREFEITURA MUNICIPAL DE PRESIDENTE PRUDENTE. Carta Planialtimétrica de Presidente Prudente. Escala: 1:10.000. Secretaria de Planejamento e Desenvolvimento Urbano. 1996.

SANTOS, Milton. A Natureza do Espaço: Técnica e Tempo, Razão e Emoção. São Paulo: Editora da Universidade de São Paulo, 2006.

SPOSITO, Maria Encarnação Beltrão. 0 chão em Presidente Prudente: a lógica da expansão territorial urbana. Pres. Prudente: FCT/UNESP, 1983. (Dissertação de Mestrado).

SUERTEGARAY, Dirce Maria Antunes. Geografia física e geomorfologia: uma (re) leitura. ljuí: Ed. Unijuí, 2002.

(Recebido em junho/2009. Aceito em setembro/2009) 